\title{
Development and Validation of a HPTLC Method for Rivaroxaban in Human Plasma for a Pharmacokinetic Study
}

\author{
A. H. SHUKLA, P. J. SHAH, P. P. DEDHIYA*, B. A. VYAS AND S. A. SHAH \\ Maliba Pharmacy College, Maliba Campus, Gopal Vidyanagar, Bardoli, Gujarat, India-394 350
}

Shukla et al.: Validated HPTLC method for determination of Rivaroxaban in human plasma

\begin{abstract}
The present study is concerned with the development and validation of a bioanalytical method for estimation of rivaroxaban in human plasma using high performance thin layer chromatography. The chromatographic separation was achieved on pre-coated silica gel $60 \mathrm{~F}_{254}$ thin layer chromatography plate using toluene:ethylacetate:methanol (6:3:1, \% v/v/v) as a mobile phase. Detection was carried out at $284 \mathrm{~nm}$. A compact spot was obtained with an $R_{f}$ value of $0.44 \pm 0.02$. The linearity was found over the concentration range of 25-125 $\mathrm{ng} / \mathrm{band}$ in human plasma. The relative standard deviation for repeatability of sample application and sample measurement was 0.60 and $1.65 \%$, respectively. The relative standard deviation for intraday and interday precisions was in the range of 1.37 to $1.85 \%$ and 1.03 to $2.77 \%$, respectively. The limit of quantitation was $8.00 \mathrm{ng} / \mathrm{band}$ and the limit of detection was $2.64 \mathrm{ng} / \mathrm{band}$. Percent recovery of rivaroxaban was in the range of $66.95-69.03 \%$. This method was applied to a pharmacokinetic study of rivaroxaban. The $\mathrm{C}_{\max }$ and $t_{\max }$ for test and marketed formulation were found to be 63.83 and $47.3 \mathrm{ng} /$ $\mathrm{ml}$ and 3 and $4 \mathrm{~h}$ respectively. The area under the curve $e_{0-\mathrm{t}}$ for test and marketed formulation were found to be 290 and $219.0 \mathrm{ng} / \mathrm{ml} \cdot \mathrm{h}$, respectively. The $t_{1 / 2}$ for test and marketed formulation was found to be 6.87 and $6.64 \mathrm{~h}$.
\end{abstract}

Key words: Rivaroxaban, method development, validation, high-performance thin-layer chromatography, pharmacokinetic study, human plasma

Rivaroxaban, 5-chloro-N-[[(5S)-2-oxo-3-[4(3-oxomorpholin-4-yl)phenyl]-1,3oxazolidin-5-yl] methyl]thiophene-2-carboxamide (fig. 1), is the first orally bioavailable oxazolidinone derivative and direct inhibitor of the coagulation factor Xa with anticoagulant activity, which has been available for prophylaxis and treatment of deep vein thrombosis ${ }^{[1-3]}$. Researchers have developed various analytical methods for estimation of rivaroxaban in its pharmaceutical dosage forms, which included high performance liquid chromatography, ultra-performance liquid chromatographic method and liquid chromatography-mass spectrometry (LC-MS $)^{[4-18]}$. Unlike high-performance thin-layer chromatography (HPTLC), the above reported methods are complex, time consuming and expensive techniques for estimation of drugs in biological samples. Therefore, this paper aimed to develop bioanalytical method for estimation of rivaroxaban in human plasma and to apply this method in a pharmacokinetic study.

*Address for correspondence E-mail: praful.dedhiya@utu.ac.in

March-April 2020

\section{MATERIALS AND METHOD}

Rivaroxaban was received as a gift sample from Symed Labs Ltd., (Hyderabad, India). Chromatography was performed on aluminum plates pre-coated with silica gel $60 \mathrm{~F}_{254}$ supplied by LobaChemie Pvt., Ltd., (Mumbai, India). Other chemicals used were toluene, methanol, ethyl acetate, acetonitrile of Analytical Reagent grade (Rankem, Thane, India). Human plasma was obtained from Sardar Smarak Hospital, Bardoli and the dosage form used was Xarelto film-coated tablets $10 \mathrm{mg}$, Bayer Zydus Pharma. Chromatographic analysis was accomplished using Linomat V semiautomatic sample

This is an open access article distributed under the terms of the Creative Commons Attribution-NonCommercial-ShareAlike 3.0 License, which allows others to remix, tweak, and build upon the work non-commercially, as long as the author is credited and the new creations are licensed under the identical terms

Accepted 10 February 2020

Revised 24 January 2020

Received 05 December 2019 Indian J Pharm Sci 2020;82(2):315-320 


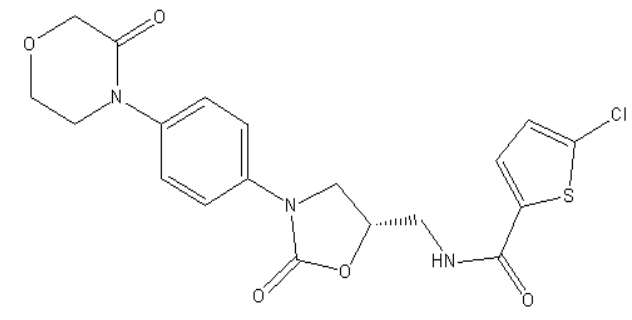

Fig. 1: Structure of rivaroxaban

applicator, Hamilton syringe $(100 \mu \mathrm{l})$, Camag TLC Scanner IV, Camag (Muttenz, Switzerland) twintrough developing chamber $(10 \times 10 \mathrm{~cm})$, ultraviolet (UV) cabinet with dual wavelength UV lamps. Electro analytical balance used was of Shimadzu, AUX-220.

\section{Preparation of standard solutions:}

Standard stock solution was prepared by dissolving $10 \mathrm{mg}$ of rivaroxaban in acetonitrile and making it up to $10 \mathrm{ml}$ with the same. Further dilutions were made to prepare 50 and $100 \mu \mathrm{g} / \mathrm{ml}$ solutions with the same solvent.

\section{Selection of mobile phase and optimized chromatographic conditions:}

Number of trials was carried out by using different solvents like toluene, methanol, ethyl acetate, chloroform, triethylamine and glacial acetic acid individually and in combinations. Bioanalytical method for estimation of rivaroxaban was developed using following chromatographic conditions. Stationary phase used was aluminum plate precoated with silica gel $60 \mathrm{~F}_{254}$ $(10 \times 10 \mathrm{~cm})$, mobile phase was toluene: ethylacetate:methanol $(6: 3: 1, \quad \% \quad \mathrm{v} / \mathrm{v} / \mathrm{v})$, chamber saturation time was kept at $30 \mathrm{~min}$, temperature was $24 \pm 2^{\circ}$, migration distance was $75 \mathrm{~mm}$ and detection wavelength was $284 \mathrm{~nm}$.

\section{Extraction of rivaroxaban from plasma:}

Five hundred microlitres of plasma was transferred into a centrifuge tube and spiked with fixed aliquots of working standard solution of rivaroxaban and vortexed, $3 \mathrm{ml}$ of acetonitrile was added and sonicated for $10 \mathrm{~min}$. The above solution was centrifuged for $15 \mathrm{~min}$ at $1000 \mathrm{rpm}$. The supernatant was transferred to a $5-\mathrm{ml}$ volumetric flask volume made up with acetonitrile and filtered through a $0.22 \mu \mathrm{m}$ syringe filter.

\section{Preparation of calibration curve:}

Aliquot 100, 200, 300, 400, and $500 \mu \mathrm{l}$ of the working standard solution $(50 \mu \mathrm{g} / \mathrm{ml})$ of rivaroxaban were spiked with $500 \mu 1 \mathrm{ml}$ of drug free plasma. Spiked plasma samples were extracted using extraction method as described above. Twenty five microlitres of the sample was spotted on a TLC plate and the plate was developed using the chromatographic conditions described above.

\section{Method validation:}

The developed bioanalytical method was validated in terms of specificity, linearity, precision, accuracy, limit of detection and limit of quantification. Specificity of the method was ascertained by analysing the standard sample and rivaroxaban extracted from plasma. The spot of rivaroxaban extracted from plasma was confirmed by comparing its $\mathrm{R}_{\mathrm{f}}$ and $\mathrm{UV}$ spectra of the spot with standard rivaroxaban. The peak purity of both the spots was assessed by comparing the spectra acquired at three different positions on the band, i.e. at peak start (s), peak apex (m) and peak end (e). Linearity for rivaroxaban in plasma was ascertained from regression coefficient by plotting graph of peak area versus respective concentration $(\mathrm{n}=5)$ by analyzing solutions corresponding to 25 to $125 \mathrm{ng} / \mathrm{band}$. Method precision was ascertained by performing repeatability of measurement, repeatability of sample application and intra-day and inter-day precisions. The accuracy of the method was determined in terms of the extraction efficiency of the method by comparing the area of rivaroxaban extracted from plasma and rivaroxaban standard. The limit of detection and limit of quantitation of the developed method were calculated from the standard deviation of the intercepts and mean slope of the calibration curves of rivaroxaban using the formula $\mathrm{LOD}=3 \sigma / \mathrm{S}$ and $\mathrm{LOQ}=10 \sigma / \mathrm{S}$, where, $\sigma$ is the standard deviation of the intercepts of 5 calibration curves and $\mathrm{S}$ is the mean slope of 5 calibration curve.

\section{Pharmacokinetic study:}

Healthy, Adult Wistar female rats (200-230 g) were obtained from the Central Animal House, Maliba Pharmacy College. The animals were housed at temperature $27 \pm 2^{\circ}$, humidity $55 \%$, 12-h light/12-h dark cycle and had free access to food and drinking water up to the time of experimentation in normal acrylic cages. The animals were acclimatized to the laboratory environment 1 week before the experiment. The experiments protocol described in the present study was approved by the Institutional Animal Ethics Committee (IAEC, Protocol No. MPC/IAEC/06 /2018) and conducted according to the Committee for the Purpose of Control and Supervision of Experiments on Animals (CPCSEA) guidelines. Five tablets of Xeralto 
of the strength $10 \mathrm{mg}$ were crushed and $8 \mathrm{ml}$ of $1 \%$ $\mathrm{CMC}$ was added to prepare a suspension. The prepared suspension was administered to rats by oral route.

\section{Blood collection and preparation of plasma sample for Pharmacokinetic studies:}

After administration of rivaroxaban to the rats, blood was collected by retro-orbital technique at $0,1,2,3$, $4,5,6,12$ and $24 \mathrm{~h}$ time intervals. One $\mathrm{ml}$ of blood was drawn into vacutainer tubes containing $1.8 \mathrm{mg}$ of EDTA. The vacutainer tubes were inverted 10 times to mix blood and the anticoagulant, centrifuged at 2000 to $3000 \mathrm{rpm}$ for $15 \mathrm{~min}$ and the supernatant was separated. Protein precipitation technique was used to prepare plasma sample for analysis. Aliquots of $0.5 \mathrm{ml}$ was taken from plasma samples collected at $0,1,2,3,4,5$, 6,12 and $24 \mathrm{~h}$. To this, $3 \mathrm{ml}$ of acetonitrile was added and vortexed, the sample was sonicated for $10 \mathrm{~min}$ and centrifuged for $15 \mathrm{~min}$ at $1000 \mathrm{rpm}$. Supernatant was transferred to a 5-ml volumetric flask diluted to the mark with acetonitrile, filtered through a $0.22 \mu \mathrm{l}$ syringe filter and $25 \mu 1$ of the filtrate was applied to the TLC plate.

\section{RESULTS AND DISCUSSION}

Numerous initial trials were carried out with toluene, methanol, ethyl acetate, chloroform and modifiers glacial acetic acid and triethylamine to determine their effect on drug migration. After these trials, various combinations of solvents, toluene:methanol:triethylamine, chloroform:methanol:glacial acetic acid, toluene:methanol, toluene:ethyl acetate:methanol were tried in various proportions. Better results were obtained in toluene:ethyl acetate:methanol in the ratio of 6:3:1, where sharp peak was observed with an $R_{f}$ of 0.44 .

Comparison of chromatograms of standard rivaroxaban and rivaroxaban from plasma showed identical $\mathrm{R}_{\mathrm{f}}$ values

of $0.44 \pm 0.02$. (fig. 2). Chromatogram of blank plasma was run to check any interference. Comparison of the spectra scanned at $\mathrm{s}, \mathrm{m}$ and e positions of individual bands showed a high degree of correlation $(>0.9994)$, which confirmed purity of the corresponding bands.

Calibration curve of rivaroxaban from plasma was obtained by plotting peak area versus concentration over the range of 25 to $125 \mathrm{ng} / \mathrm{band}$. The calibration curve was found to be linear with a correlation coefficient of 0.9954 . 3D chromatogram is shown in fig. 3. Calibration data is shown in Table 1. RSD for repeatability of measurement and repeatability of sample application was found to be 0.60 and $1.65 \%$, respectively, which ensured precision of spotter device. RSD for intra-day and inter-day precision was found in the range of 1.37-1.85 and 1.03-2.77\%, respectively. These results indicated that the method is reproducible and could be used for estimating rivaroxaban in plasma.

The minimum detectable concentration in terms of LOD and the minimum quantifiable concentration in terms of LOQ were found to be 2.64 and $8.00 \mathrm{ng} / \mathrm{band}$, respectively, which indicated good sensitivity of the method. The accuracy of the method in terms of extraction efficiency was determined for rivaroxaban from plasma and \% recovery was found to be in the range of 66.95 to $69.03 \%$ (Table 2). Robustness of the method was determined by changing mobile phase composition, mobile phase volume, saturation time, wavelength and scanning speed. The $\%$ RSD was found in the range of 1.32-1.67, which

\section{TABLE: 1 CALIBRATION DATA FOR RIVAROXA- BAN IN PLASMA}

\begin{tabular}{lcc}
\hline Amount $(\mathrm{ng} /$ band $)$ & Peak area $($ Mean \pm SD, $\mathrm{n}=5)$ & $\%$ RSD \\
\hline 25 & $617.0 \pm 15.2$ & 2.46 \\
50 & $1025.9 \pm 23.9$ & 2.32 \\
75 & $1439.6 \pm 26.0$ & 1.81 \\
100 & $1776.3 \pm 21.6$ & 1.21 \\
125 & $2080.3 \pm 37.2$ & 1.78 \\
\hline
\end{tabular}

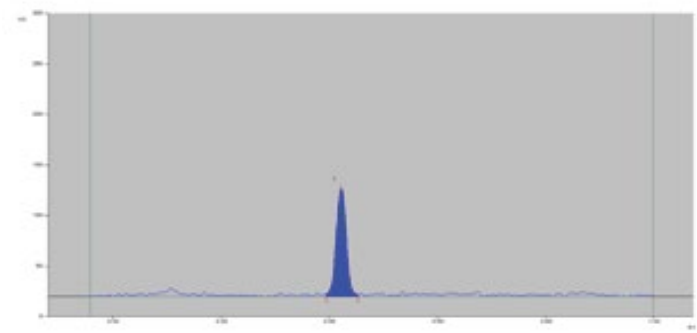

a)

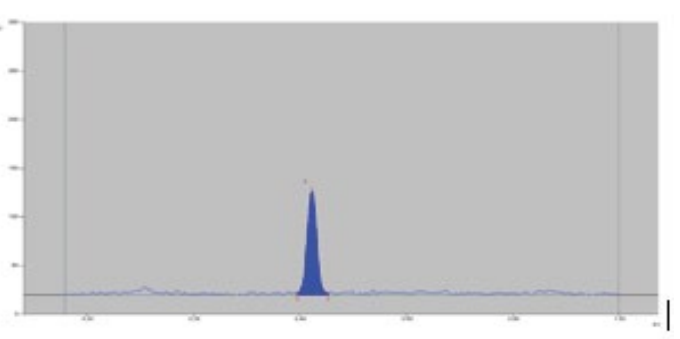

b)

Fig. 2: Densitogram of rivaroxaban Densitograms of rivaroxaban a) standard and b) from plasma 
ensured robustness of the method (Table 3 ). The overall validation summary is given in Table 4.

Pharmacokinetic studies of the test (solid dispersion based tablet) and a marketed formulation (Xarelto tablet) were conducted in female Wistar rats after oral administration and sampling was done via retroorbital vein. The plasma concentration was calculated for samples collected at different time intervals

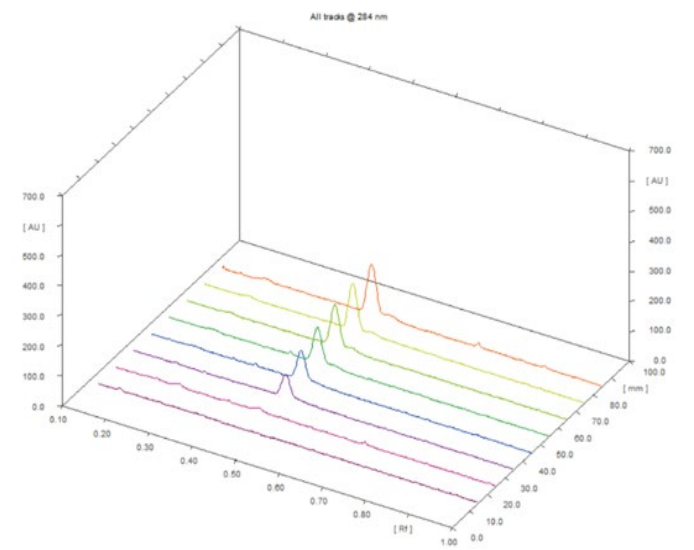

Fig. 3: 3D chromatogram of calibration range of rivaroxaban from plasma

TABLE 2: RECOVERY DATA OF RIVAROXABAN FROM PLASMA

\begin{tabular}{lccc}
\hline $\begin{array}{l}\text { Amount } \\
(\mathrm{ng} / \text { band })\end{array}$ & $\begin{array}{c}\text { Standard } \\
\text { Peak area } \pm \text { SD } \\
(\mathrm{n}=5)\end{array}$ & $\begin{array}{c}\text { From plasma } \\
\text { Peak area } \pm \text { SD } \\
(\mathrm{n}=5)\end{array}$ & \% Recovery \\
\hline 25 & $893.8 \pm 6.7$ & $617.0 \pm 15.2$ & 69.03 \\
50 & $1506.2 \pm 6.6$ & $1025.9 \pm 23.9$ & 68.11 \\
75 & $2132.4 \pm 11.7$ & $1439.6 \pm 26.0$ & 67.51 \\
100 & $2649.6 \pm 6.8$ & $1776.3 \pm 21.6$ & 67.04 \\
125 & $3107.7 \pm 12.0$ & $2080.9 \pm 37.2$ & 66.95 \\
\hline
\end{tabular}

TABLE 3: ROBUSTNESS DATA FOR RIVAROXABAN using above obtained regression line Eqn.. Data for pharmacokinetic study is depicted in Tables 5 and 6, which was calculated through PK solver (excel add in). Comparison of plasma concentration versus time profile of test and marketed formulation is shown in fig. 4. The values of $t_{1 / 2}$ for test and marketed formulation was found to be 6.87 and $6.64 \mathrm{~h}$, respectively, which showed no significant difference between the $t_{1 / 2}$ values suggesting similar time for elimination of rivaroxaban from both the formulations.

The $\mathrm{C}_{\max }$ value for test and marketed formulation were found to be 63.83 and $47.3 \mathrm{ng} / \mathrm{ml}$, respectively. The statistical analysis showed significant difference between these $\mathrm{C}_{\max }$ values $\mathrm{P}<0.05$. The $\mathrm{C}_{\max }$ of the test formulation is 1.35 times higher than that of the marketed formulation. This suggested better release

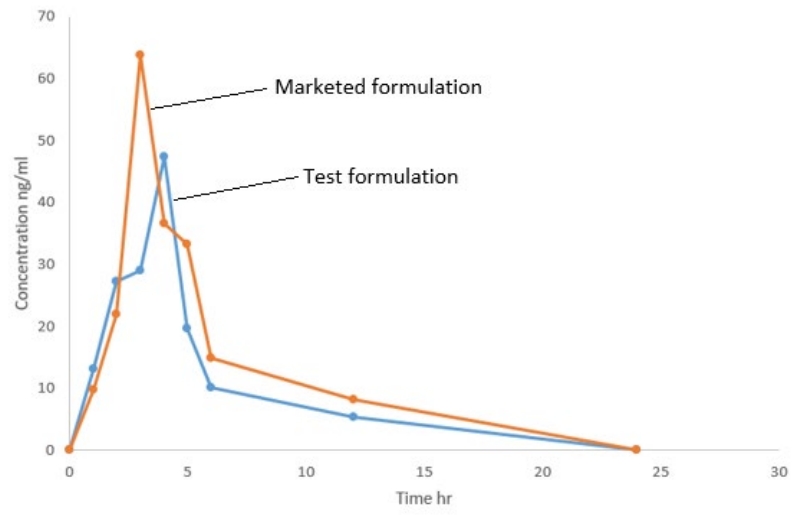

Fig. 4: Overlay of plasma concentration versus time profile of rivaroxaban

Overlay of plasma concentration versus time profile of rivaroxaban from $(-\lambda-)$ Xarelto tablet and $(-\lambda-)$ test formulation

\begin{tabular}{|c|c|c|c|c|}
\hline Parameters & $\begin{array}{l}\text { Robustness } \\
\text { condition }\end{array}$ & Peak area & $\begin{array}{c}\text { Mean Peak area } \\
\pm \text { SD }\end{array}$ & $\%$ RSD \\
\hline \multirow{5}{*}{$\begin{array}{l}\text { Mobile phase composition } \\
\text { (toluene:ethyl acetate:methanol) }\end{array}$} & $7: 2.5: 0.5, \mathrm{v} / \mathrm{v} / \mathrm{v}$ & 1403.5 & \multirow{5}{*}{$1429.68 \pm 23.99$} & \multirow{5}{*}{1.67} \\
\hline & $5: 3.5: 1.5, \mathrm{v} / \mathrm{v} / \mathrm{v}$ & 1450.4 & & \\
\hline & $6: 3.5: 0.5, v / v / v$ & 1447.7 & & \\
\hline & $6: 2.5: 1.5, \mathrm{v} / \mathrm{v} / \mathrm{v}$ & 1403.6 & & \\
\hline & $6: 3: 1, v / v / v$ & 1443.2 & & \\
\hline \multirow{3}{*}{ Mobile phase volume } & $9 \mathrm{ml}$ & 1410.9 & \multirow{3}{*}{$1435.47 \pm 23.08$} & \multirow{3}{*}{1.61} \\
\hline & $10 \mathrm{ml}$ & 1438.8 & & \\
\hline & $11 \mathrm{ml}$ & 1456.7 & & \\
\hline \multirow{3}{*}{ Saturation time } & $20 \min$ & 1440.3 & \multirow{3}{*}{$1454.93 \pm 20.84$} & \multirow{3}{*}{1.43} \\
\hline & $30 \mathrm{~min}$ & 1445.7 & & \\
\hline & $40 \min$ & 1478.8 & & \\
\hline \multirow{3}{*}{ Wavelength } & $281 \mathrm{~nm}$ & 1432.8 & \multirow{3}{*}{$1423.87 \pm 19.13$} & \multirow{3}{*}{1.34} \\
\hline & $284 \mathrm{~nm}$ & 1436.9 & & \\
\hline & $287 \mathrm{~nm}$ & 1401.9 & & \\
\hline \multirow{3}{*}{ Scanning speed } & $10 \mathrm{~mm} / \mathrm{sec}$ & 1436.8 & \multirow{3}{*}{$1446.60 \pm 19.17$} & \multirow{3}{*}{1.32} \\
\hline & $20 \mathrm{~mm} / \mathrm{sec}$ & 1434.3 & & \\
\hline & $40 \mathrm{~mm} / \mathrm{sec}$ & 1468.7 & & \\
\hline
\end{tabular}


TABLE 4: METHOD VALIDATION SUMMARY FOR RIVAROXABAN IN PLASMA

\begin{tabular}{|c|c|}
\hline Parameters & Result \\
\hline Linearity range & $25-125 \mathrm{ng} / \mathrm{band}$ \\
\hline Regression equation & $Y=14.71 x+284.52$ \\
\hline Regression coefficient (R2) & 0.9954 \\
\hline Precision (RSD) & \\
\hline Repeatability of measurement $(n=7)$ & 0.60 \\
\hline $\begin{array}{l}\text { Repeatability of sample application } \\
(\mathrm{n}=7)\end{array}$ & 1.65 \\
\hline Intra-day precision $(n=3)$ & $1.37-1.85$ \\
\hline Inter-day precision $(n=3)$ & $1.03-2.77$ \\
\hline Limit of detection (LOD) & $2.64 \mathrm{ng} / \mathrm{band}$ \\
\hline Limit of quantification (LOQ) & $8.00 \mathrm{ng} / \mathrm{band}$ \\
\hline Recovery $(n=3)$ & $66.95-69.03 \%$ \\
\hline Robustness & Robust \\
\hline
\end{tabular}

TABLE 5: IN-VIVO DRUG RELEASE PROFILE OF RIVAROXABAN

\begin{tabular}{lcc}
\hline Time & Test formulation & \multicolumn{2}{c}{$\begin{array}{c}\text { Marketed formulation } \\
\text { (h) }\end{array}$} & $\begin{array}{c}\text { Mean concentration } \pm \text { SD } \\
(\mathrm{ng} / \mathrm{ml}, \mathrm{n}=3)\end{array}$ & $\begin{array}{c}\text { Mean Concentration } \pm \text { SD } \\
(\mathrm{ng} / \mathrm{ml}, \mathrm{n}=3)\end{array}$ \\
0 & 0 & 0 \\
1 & $9.81 \pm 1.26$ & $13.17 \pm 1.71$ \\
2 & $21.83 \pm 4.21$ & $27.21 \pm 2.98$ \\
3 & $63.83 \pm 4.19$ & $29.0 \pm 1.36$ \\
4 & $36.63 \pm 3.20$ & $47.3 \pm 2.76$ \\
5 & $33.2 \pm 1.30$ & $19.66 \pm 1.66$ \\
6 & $14.8 \pm 1.96$ & $10.22 \pm 1.10$ \\
12 & $8.13 \pm 1.16$ & $5.46 \pm 1.86$ \\
24 & 0 & 0 \\
\hline
\end{tabular}

TABLE 6: DATA OF PHARMACOKINETIC STUDY FOR RIVAROXABAN

\begin{tabular}{lcc}
\hline Parameters & Test formulation & Marketed formulation \\
\hline $\mathrm{C}_{\max }(\mathrm{n}=3)$ & $63.83 \pm 2.47 \mathrm{ng} / \mathrm{ml}$ & $47.3 \pm 1.92 \mathrm{ng} / \mathrm{ml}$ \\
$\mathrm{t}_{\max }$ & $3 \mathrm{~h}$ & $4 \mathrm{~h}$ \\
$\mathrm{AUC}$ & $290.7 \mathrm{ng} / \mathrm{ml} . \mathrm{h}$ & $219.9 \mathrm{ng} / \mathrm{ml} . \mathrm{h}$ \\
Half-life & $6.87 \mathrm{~h}$ & $6.64 \mathrm{~h}$ \\
\hline
\end{tabular}

of rivaroxaban from the test formulation. The $T_{\text {max }}$ of the test formulation occurred at $3 \mathrm{~h}$ as compared to $4 \mathrm{~h}$ for the marketed formulation. These values indicated a rapid onset of action of the test formulation. Based on the $\mathrm{C}_{\max }$ and $\mathrm{T}_{\max }$ values it could be concluded that the test formulation exhibited greater and faster onset of absorption. The $\mathrm{AUC}_{0-\mathrm{t}}$ for the test and the marketed formulation was found to be 290.7 and $219.90 \mathrm{ng} / \mathrm{ml}$.h, respectively. The AUC of test formulation was 1.32 times higher as compared to the marketed formulation indicating better rivaroxaban bioavailability from the test formulation compared to the marketed formulation.
In conclusion, the present work involved development and validation of a HPTLC method for the estimation of rivaroxaban in plasma. The developed method was found to be specific, precise, accurate and robust. The method was applied to a pharmacokinetic study of rivaroxaban. The results indicated better release, faster onset of action and better bioavailability of the test formulation compared to the marketed formulation. Although the present method showed considerable recovery of rivaroxaban from plasma, other extraction methods such as solid phase extraction could have been tried for obtaining a greater recovery of rivaroxaban. The present study could also be extended to estimation of rivaroxaban in urine.

\section{Acknowledgements:}

The authors thank Symed Labs limited, Hyderabad, India for providing rivaroxaban as a gift sample and Maliba Pharmacy College for providing the required facilities to carry out this research work.

\section{REFERENCES}

1. Chandra B, Vankayalapati H, Mittapalli R, Anaparthi S. Development and validation of UV spectrophotometric method for the determination of Rivaroxaban. Der Pharma Chemica. 2013;5(4):1-5.

2. Wolfgang M, Jan S, Dagmar K, and Michael B. Clinical pharmacokinetic and pharmacodynamic profile of Rivaroxaban. Clin Pharmacokinet 2014;53(1):1-16.

3. Timothy B. Experimental and clinical pharmacology, new Oral Anticoagulant Drugs-Mechanisms of Action. Aust Prescr 2010;33(2):38-41.

4. Attimarad M, Ahmed KK, Aldhubaib BE, Harsha S. Highperformance thin layer chromatography: A powerful analytical technique in pharmaceutical drug discovery. Pharm Methods 2011;2(2):71-5.

5. Mohamed A, Medhat A, Hayam M. Investigation of the profile and kinetics of degradation of Rivaroxaban using HPLC, TLCdensitometry and LC/MS/MS: application to pre-Formulation studies. Bull Fac Pharm Cairo Univ 2015;53(1):53-61.

6. Kasad PA, Muralikrishna K. Area under curve Spectrophotometric method for determination of Rivaroxaban in bulk and tablet formulation and its validation. Asian J Pharm Sci 2013; 3(3):109-13.

7. Shivashankar V, Gandhimanthi M, Ravi TK. Development of validated RP-HPLC method for estimation of Rivaroxaban in pharmaceutical formulation. Int $\mathrm{J}$ Pharm Anal Res 2015;4(4):406-10.

8. Mustafa C, Tuba R, Engin K, Sacide A. RP-HPLC method development and validation for estimation of Rivaroxaban in pharmaceutical dosage forms. Braz J Pharm Sci 2013;49:2.

9. Basima A, Mohammad A, Francois K, Manal D, Fida A, Alyamama A. Development and validation of a liquid chromatography method for the analysis of Rivaroxaban and determination of its production related impurities. Pharm Chem J 2018;52:483-90. 
10. Burla S, Peruri V, Chandra B. Application of stability indicating HPLC method with UV detector to the analysis of Rivaroxaban in bulk and tablet dosage form. Chem Sci Trans 2014;3(4):1546-54.

11. Nageswara R, Ramakrishna K. Development and validation of a stability indicating LC-PDA-MS/MS method for separation, identification and characterization of process related and stress degradation products of Rivaroxaban. RSC Adv 2014;4(44):231-55.

12. Rohde G. Determination of Rivaroxaban - A novel, oral, direct factor Xa inhibitor - In human plasma by high-performance liquid chromatography-tandem mass spectrometry. J Chromatogr B 2008;872:43-50.

13. Yadav S, Dubey N. Development and validation of bioloanalytical method for estimation of Rivaroxaban using HPLC-PDA in human blood plasma. J Drug Deliv Ther 2017;7(7):123-5.

14. Derogis P, Sanches L, Aranda V, Colombini M, Mangueira C, Katz M, et al. Determination of Rivaroxaban in patient's plasma samples by anti-xa chromogenic test associated to high performance liquid chromatography tandem mass spectrometry (HPLC-MS/MS). Plos One 2017;12(2):1-14.

15. Rajan N, AnverBasha K. A stability-indicating ultraperformance liquid chromatographic method for estimation of related substances and degradants in Rivaroxaban active pharmaceutical ingredient. J Pharm Res 2014;8(11):1719-25.

16. Patil P, Wawdhane S, Chaudhari P. Identification, separation and characterization of acidic and alkali degradation of Rivaroxaban under ICH recommended stress condition by HPTLC with MS/TOF. Anal Chem Lett 2017;7(5):706-23.

17. Vaghela D, Patel P. High performance thin layer chromatographic method with desitometry analysis for determination of Rivaroxaban form its tablet dosage form. Int J Pharm Pharm Sci 2014;6(6)383-6.

18. Lories I, Mostafa A, Girges. High performance liquid chromatography, TLC densitometry, first-derivative and first-derivative ratio spectrophotometry for determination of Rivaroxaban and its alkaline degradates in bulk powder and its tablets. J Chromatogr Sep Tech 2013;4:1-6. 